\title{
Adolescent Personality Pathology and the Alternative Model for Personality Disorders: Self Development as Nexus
}

\author{
Carla Sharp \\ Department of Psychology, University of Houston, Houston, TX, USA
}

\section{Keywords}

Adolescence $\cdot$ Personality disorder · DSM-5 alternative model

\begin{abstract}
This paper reviews maladaptive trait development (DSM-5 Section III Criterion B), the development of DSM-5 Section II borderline personality disorder, and research on the development of identity, self-direction, empathy/mentalizing, and intimacy (DSM-5 Section III Criterion A). Combined, these previously disparate literatures begin to point to an integrated developmental theory of personality pathology, which suggests that Criterion A concepts (identity, self-direction, empathy, and intimacy) coalesce around the development of self, marking a discontinuous (qualitative) developmental shift. This developmental shift is a function of the demands placed on individuals to take on independent adult role function, combined with biologically-based maturational cognitive and emotional advances during adolescence. Section II personality disorder ensues when an integrated and coherent sense of self fails to develop, resulting in nonfulfilment of adult role function. In this sense, Criterion A self function can account for the onset of Section II personality disorder in adolescence, while Criterion B provides a useful descriptive account of continuous aspects of personality function over time.

(c) 2020 S. Karger AG, Basel
\end{abstract} ity Disorders (AMPD) in DSM-5 Section III allows for a developmentally sensitive elaboration of maladaptive personality in two important ways. First, the AMPD legitimizes a dimensional trait perspective (Criterion $\mathrm{B}$ ), which facilitates the integration of decades of developmental temperament and trait research [1-4] into more recent research on personality disorder in youth $[5,6]$. Second, the AMPD legitimizes maladaptive self and interpersonal function (Criterion A), as a unidimensional severity continuum, as the common and core feature shared by all personality pathology, regardless of Criterion B "flavor." In so doing, the AMPD facilitates the integration of developmental research on constructs such as identity, self-directedness, empathy, and intimacy with what is currently known about Section II personality disorder in adolescents. Combined, these previously disparate literatures begin to point to an integrated developmental theory of personality pathology, which in abbreviated form suggests the following: Already at birth, a child's position on any dispositional trait dimension (Criterion B) can be readily identified and recognized. While research suggest a normative increase in maladaptive personality traits in adolescence, followed by a normative decline thereafter, children's position on Criterion B dimensions relative to their 
same-age peers remains relatively stable throughout development. And while children as young as infants may evidence extreme scores on temperamental measures indicative of maladaptive trait function, they are not diagnosed with personality disorder before adolescence, because until adolescence, there is a limited requirement placed on children to acquire the new level of knowledge, skills, and cultural competence to successfully transition to an independent adult role [7]. Therefore, adolescence ushers in a qualitatively distinct maturational period where, in order to take on adult rights, responsibilities, and social and occupational roles, certain functions, subserved by qualitative shifts in cognitive and neural maturation, must come on line [7]. Many of these functions fall within the purview of identity, self-direction, empathy, and intimacy - in short, Criterion A - but coalesce around the development of self. In sum then, viewed through a developmental lens, Criterion B represents developmental continuity in personality pathology, while Criterion A represents developmental discontinuity. As such, Criterion $\mathrm{A}$, but not Criterion $\mathrm{B}$, can account for the onset of personality disorder in adolescence. To build this argument, I will begin by reviewing the developmental literature on maladaptive trait (Criterion B) development. I will then review the current knowledge base on Section II personality disorder in adolescence (in particular borderline personality disorder [BPD]), followed by a review of developmental research on concepts associated with Criterion A function: identity, self-direction, empathy, and intimacy, explaining how Criterion A concepts are interconnected to facilitate the development of self, thereby marking a qualitative shift in personality development referred to as the "binding" of personality.

\section{Maladaptive Trait (Criterion B) Development}

Research conducted over the last 30 years on maladaptive trait development is best represented by the developmental personality-psychopathology spectrum approach [1-3, 8-12]. According to this approach, personality begins with temperamental traits already observable during infancy and toddlerhood, which make up the entirety of personality during the early years $[8,13]$. Temperament describes the initial state from which personality develops and links individual differences in behavior to genetic endowment and underlying neural networks [14]. The original dimensions described by Thomas and Chess [15] on which children show variability in their reactions to the environment included activity level, approach/withdrawal, intensity

The Alternative Model for Personality Disorders threshold, adaptability, rhythmicity, mood, attention span, persistence, and distractibility. These dimensions were later refined to include the broad dimensions of effortful control, negative affectivity, and extraversion/surgency [4]. These dimensions appear to be valid cross-culturally [16] and demonstrate strong similarities to the structure of temperament in other animals [4] as well as to the Big Five personality factors of Extraversion (extraversion/surgency), Neuroticism (negative affectivity), and Conscientiousness (effortful control) [17]. Research investigating the links between these temperamental dimensions and symptoms of emotional and behavior disorders suggest that temperamental traits are explained by an underlying two-factor model of internalizing and externalizing behavior [18]. Similarly, research using personality (not temperament) measures has consistently replicated adult findings for a five-factor structure of typical $[19,20]$ and maladaptive trait function in childhood and adolescence [21], which are also subsumed by the two-dimensional spectra of internalizing and externalizing behavior [22].

The implication of this developmental model of personality-psychopathology spectrum is that internalizing and externalizing pathology constitute the severe (extreme) end on a dimensional continuum of temperamental/personality traits. For instance, externalizing disorders are seen as extreme variants of the trait of Disinhibition, and depression and anxiety constitute the extreme variant of the trait of Negative Affectivity [8]. Similarly, personality disorder is conceptualized from this perspective as extreme variants of basic traits, such that early individual differences in Emotional Stability, Extraversion, Imagination/Openness, Agreeableness, and Conscientiousness as represented by the five-factor model are seen to be meaningfully related to each of the DSM-based personality disorders in a largely similar way as has been demonstrated for adults and youth [10].

Two important take-home messages are derived from the developmental personality-psychopathology spectrum approach to personality. First, trait-defined personality is weaved into, or subserves, all manifestations of psychopathology [23]; and second, it suggests developmental continuity in personality development in that underlying structural features are understood within the same dimensional hierarchical framework across different age periods. Put differently, according to this model, whether one is interested in temperament in a 2-year-old, the Big Five in an 8-year-old, or maladaptive trait function in a 15- or 34-year-old, the same five-factor structure subserved by the two-dimensional internalizing/externalizing spectra explains the organization of behavior. 


\section{Section II Personality Disorder in Adolescence}

Over the last $10-15$ years, there has been a proliferation of research in adolescents using narrow-band measures of DSM-IV or DSM-5 Section II-defined personality disorder, in particular BPD. Although not in line with recent trends towards more dimensionally defined constructs of psychopathology [24], this research, which relies on more traditional DSM-based concepts such as $\mathrm{BPD}$, was important for clinical reasons. Specifically, at the time of its inception, clinicians were (and sometimes still are) reluctant to identify and treat young people with personality challenges, resulting in these youngsters not receiving the help they needed [25]. Therefore, it was important, from a clinical standpoint, to demonstrate validity and reliability of DSM-sanctioned constructs such as BPD in adolescence so that the many evidence-based treatments that were developed for adult BPD could be evaluated for efficacy in young people, in addition to the development of preventative efforts. Reluctance in assessing and treating adolescent BPD was based on a variety of myths about personality disorder in adolescence, which have now been shown to be unsupported by the evidence as reviewed elsewhere [23, 26-28]. In short, we now know that Section II personality disorder, categorically defined, can be reliably and validly assessed in 12- to 17-year-olds. A wide variety of interview-based and self-report measures have been developed and validated. These measures show strong and similar psychometric properties in the assessment of Section II BPD in adolescents as in adults [6]. Using these measures, several studies have evaluated the prevalence of Section II BPD in adolescents and have shown that rates mirror those of adults - e.g., $3 \%$ in the United Kingdom [29] and the United States [30] and 2\% in China [31]. Using narrow-band, continuously scored measures of borderline symptoms, research has demonstrated the onset of BPD to occur in adolescence [32]. Research using validated measures of Section II BPD in adolescence has also demonstrated very similar correlates, risk factors, and antecedents to studies conducted in adults [33]. Important in this regard have been consistent findings that Section II BPD is preceded by a comorbid pattern of internalizing and externalizing behavior in preadolescence, but not the other way round [34]. Moreover, when Section II BPD (as a continuous or categorical variable) is entered into hierarchical regression analyses to assess its incremental value in predicting relevant outcomes, it appears to add not only statistically, but also clinically significant predictive value to the model [3537]. Therefore, Section II BPD appears to add unique pre- dictive value to outcomes above and beyond that of internalizing/externalizing spectra disorders. Furthermore, in answer to concerns over Section II BPD being distinguishable from typical adolescent "storm and stress," studies have consistently shown Section II-defined BPD groups to show increased levels in a variety of maladaptive correlates (e.g., mentalizing, experiential avoidance, emotion dysregulation) compared to both psychiatric (adolescents with internalizing and externalizing disorders, but without Section II-defined BPD) and healthy controls [35, 38-40]. Finally, Section II-defined BPD appears to be as treatable in youngsters as it is in adults [6], with similar effect sizes for treating depression [41].

Taken together, this research, which has used more traditional criteria for establishing the validity of a diagnosis [42], has firmly established the diagnosis of Section II BPD in adolescence and its importance as a novel public health problem [25]. However, that Section II BPD indexes a form of psychopathology that can be reliably distinguished from the internalizing-externalizing spectra in both phenomenology and course should be interpreted against the background of the failure to substantiate a ten-factor solution explaining covariance among personality disorder symptoms. This failure has rightly led to concerns over the validity of the construct of Section II BPD [43-45]. While we have been in full agreement with these concerns, we have argued that Section II BPD (like Criterion A) may represent the common or core features shared by all personality pathology [46-49]. This argument is based on (1) the fact that, compared to other personality disorders, which were largely reduced to purely behavioral manifestations of personality pathology with the transition to DSM-IV, BPD still contains explicit criteria reflective of intrinsic maladaptive self and interpersonal function, and (2) recent empirical evidence that BPD appears to load exclusively onto a general factor of personality pathology (gPD), while other Section II personality disorders appear to represent specific factors or maladaptive trait constellations [50-52]. It remains, of course, an empirical question to what extent Section II BPD fully captures gPD and therefore Criterion $A$, but given the suggested overlap (at least in adults), it is possible to argue that $\mathrm{BPD}, \mathrm{gPD}$, or Criterion A represents an index of increased severity in psychopathology [48, 49, $53,54]$, somewhere along the severity pathway between the internalizing-externalizing spectra and psychoticism [55, 56]. The question then becomes why Section II BPD, gPD, or Criterion A onsets only in adolescence. Indeed, I will argue that the suggested overlap between Section II BPD, gPD, and Criterion A becomes apparent only in adolescence, because adolescence is associated with a distinct pe- 
riod of rapid (and in some cases qualitative and therefore discontinuous) developmental changes in Criterion A function, which, as I will show, coalesce around the core concept of self function.

\section{Developmental Research on Criterion A Function: Self Development as Nexus}

Criterion A covers a vast array of constructs across self and interpersonal function. Regarding self function, Criterion A evaluates the extent to which an individual demonstrates integrated identity function (unique sense of self, stable and accurate self-esteem, and adequate selfregulation) as well as self-direction (meaningful shortterm and life goals, adequate standards of behavior, and self-reflection). Regarding interpersonal function, Criterion $\mathrm{A}$ evaluates the extent to which an individual shows empathy or mentalizing capacity (comprehension of others, tolerance of differing perspectives, and understanding the impact of their behavior on others) as well as the capacity for intimacy (depth and duration of a meaningful connection with others, the desire and capacity for closeness, and mutuality of regard for others). Since Criterion A was only introduced in the DSM system in 2013, it will take time for research to accumulate on the developmental course of Criterion A function exactly as it is presented in the DSM-5. In addition, many conceptual and methodological issues have to be addressed in order to adequately chart the developmental course of DSM-5-based Criterion $\mathrm{A}$ function. For instance, measures of Criterion $\mathrm{A}$ seem to suggest a 4 (identity, self-direction, intimacy, empathy) $\times 3$ (components of each construct) $\times 5$ (levels) matrix, while the original conceptualization of Criterion A was suggested to be unidimensional [57]. While the field awaits these clarifications, it is worth delving into the rich, deep, and broad developmental literature on the typical development of the concepts that make up Criterion A. For instance, much is known about the typical development of identity, self-esteem, self-regulation, self-reflection, goal-setting, perspective-taking, comprehension of others, and the quality and duration of close relationships in children and adolescents, and as it turns out, all of these developmental processes coalesce to support the development of an integrated sense of self [58] (in this sense, a developmental perspective would argue in favor of Criterion $\mathrm{A}$ as unidimensional, or constituting a general and specific factor structure). While a full and detailed review of this literatures is beyond the scope of this article, I will present it here in abbreviated form to show how the onset

The Alternative Model for Personality Disorders of Section II personality disorder in adolescence can be explained with self development as nexus.

As Erikson [59] pointed out 70 years ago, one of the major tasks of adolescence is the establishment of a coherent and integrated sense of self. The establishment of a coherent and integrated sense of self is a precondition for successfully taking on independent and autonomous adult roles and responsibilities that facilitate contributions to society and procreation [7]. To achieve this, adolescents must successfully navigate the process of becoming a separate individual while remaining connected to others - most notably parental attachment figures. The normative and neurobiologically-based increase in risktaking and exploration behaviors help facilitate the push towards independence [60], alongside significant advances in the metacognitive capacity for self-reflection that facilitates the ability to, for the first time, ask questions such as "Who am I?," "How do I want others to view me?," and "How do I fit into the larger social world?" [58]. The developmental building blocks of these capacities are of course observable from early childhood onwards. Preadolescent children are, for instance, able to compare different attributes about the self. We are also able to chart adaptive and maladaptive function in Criterion A-related concepts (e.g., delayed mentalizing ability, reduced empathy, problems in self-regulation). However, it is not until adolescence that young people are able to integrate varying abstract concepts into a coherent and organized whole. By late adolescence, they rely much less on direct social comparison with peers or feedback from others and begin to adhere to a view of themselves in terms of personal standards and moral beliefs associated with increases in selfdirectedness and self-esteem [61]. Therefore, while the disparate aspects of Criterion A are as readily observable in preadolescence as are traits, the coalescing of these aspects into a unidimensional severity continuum does not come together ("bind") until adolescence. Here, I argue for self as the nexus around Criterion A aspects coalesces.

McAdams and Olson [62] state that it is during adolescence that the "binding" of the personality begins, because, for the first time, metacognitive capacities are mature enough to handle the work of holding in balance different views of the self-in-relation-to-others. The development of self builds on a strong foundation of prior and continuing attachment security with parents and high-quality relationships with peers $[63,64]$. In turn, an integrated sense of self facilitates the maintenance of strong interpersonal relationships within and outside the home. Strong attachments to parents and peers and interpersonal effectiveness are facilitated by the capacity for empathy or mentalizing, which 
shows rapid growth and expansion in adolescence - in some cases reflecting discontinuous maturational shifts. In particular, social neuroscience research suggest an anterior-to-posterior developmental shift in brain regions supporting mentalizing during adolescence. The well-validated linear age-related decline in dorsomedial prefrontal cortex responses during mentalizing tasks appears to be joined by linear and nonlinear (discontinuous) patterns of developmental change in other regions associated with simulation, which are highly sensitive to affective contributions [65]. The proliferation of the social brain in terms of perspective-taking, mentalizing, and empathy also allows for the development of social emotions such as shame and guilt, which facilitates adult moral functioning and allows the young adult to begin to regulate the self within his/her social context. With the expansion of the social brain, in conjunction with qualitative (discontinuous) shifts in sexual maturity and identity, adolescents are poised for adult intimacy, again informing the developing self in significant ways. Identity, self-direction, intimacy, and empathy are therefore intractably linked and remain interconnected through adolescence into adulthood to support the development of self [66].

In summary, developmental research suggests that Criterion A concepts (identity, self-direction, empathy, and intimacy) coalesce around the development of self, marking a discontinuous (qualitative) shift in development that enables the adolescent to take on independent adult role function, which is demanded from the environment. The concepts of developmental continuity and discontinuity are well known in developmental psychology and developmental psychopathology [67]. Maturation that is continuous does not change in structure or form, but follows a continuous course - for instance, height. In contrast, maturation that is discontinuous (e.g., the development of primary and secondary sexual characteristics) involves qualitative change. Whether maturation is continuous or discontinuous may be important for a variety of reasons; however, it seems more important to focus attention on the extent to which developmental changes, whether continuous or discontinuous, transform functioning. For instance, locomotion markedly increases a toddler's ability to explore and control their environment, and the development of language opens up new opportunities for social communication [67]. Similarly, the development of an integrated and coherent sense of self changes the adolescent's psychological situation to the degree that they are able to begin taking on adult social role function ("work and love"). Trait development (which represents a continuous change process) does not appear to have the same transforming quality, probably because it is descriptive in nature. Thus, while a developmental course for trait function has been described, the ebb and flow of trait development cannot account for the onset of Section II personality disorder in adolescence. Put differently, traits are unable to explain changes in behavior during different age periods and can therefore not account for the onset of personality disorder in adolescence. Here, I argue that personality disorder ensues when an integrated and coherent sense of self fails to develop, resulting in nonfulfilment of adult role function. Adaptive self function (which is intractably linked to adaptive interpersonal function) constitutes a developmental milestone that, if missed, impedes the binding of personality and ultimately the transformation from child to adult personality function.

\section{Clinical Implications and Future Research Directions}

While the empirical research reviewed in this paper reasonably points to the views presented here, several hypotheses remain untested. Longitudinal data that chart the developmental course of aspects of DSM-5 Criterion $A$ in conjunction with measures of Criterion $B$ and more traditional measures of psychopathology (e.g., Section II BPD and measures of the internalizing-externalizing spectra) can clarify the respective contributions of Criteria $\mathrm{A}$ and $\mathrm{B}$ in (1) explaining the onset of personality pathology and (2) disentangling (or confirming overlap) between Criterion A, Criterion B, and the internalizing-externalizing spectra. If it is indeed true that Criterion A accounts for the binding of personality into a unidimensional severity continuum during adolescence, then it is important that interventions explicitly scaffold this binding. Elsewhere, we have argued that interventions aimed at enhancing mentalizing capacity during adolescence are key to healthy personality development $[54,68]$. These interventions focus on slowing down thinking and feeling around self and others so that an adaptive and integrated sense of self emerges that can effectively guide the important decisions adolescents take as they age into adulthood.

\section{Disclosure Statement}

The author has no conflicts of interest to declare.

\section{Funding Sources}

None. 


\section{References}

1 De Clercq B, De Fruyt F, Widiger TA. Integrating a developmental perspective in dimensional models of personality disorders. Clin Psychol Rev. 2009 Mar;29(2):154-62.

2 Shiner JL, Tackett JL. Personality disorders in children and adolescents. In: Mash EJ, Barkley RA, editors. Child psychopathology. New York: Guilford Press; 2014. p. 848-96.

3 Shiner RL. The development of personality disorders: perspectives from normal personality development in childhood and adolescence. Dev Psychopathol. 2009;21(3):715-34.

4 Rothbart MK, Bates JE. Temperament. In: Damon W, Lerner R, Eisenberg N, editors. Handbook of child psychology. Vol. 3: Social, emotional, and personality development. New York: Wiley; 2006. p. 99-166.

5 Chanen AM. Borderline Personality Disorder in Young People: Are We There Yet? J Clin Psychol. 2015 Aug;71(8):778-91.

6 Sharp C, Fonagy P. Practitioner Review: borderline personality disorder in adolescence recent conceptualization, intervention, and implications for clinical practice. J Child Psychol Psychiatry. 2015 Dec;56(12):1266-88.

7 Dahl RE, Allen NB, Wilbrecht L, Suleiman $\mathrm{AB}$. Importance of investing in adolescence from a developmental science perspective. Nature. 2018 Feb;554(7693):441-50.

8 Tackett JL. Evaluating models of the personality-psychopathology relationship in children and adolescents. Clin Psychol Rev. 2006 Sep;26(5):584-99.

9 Forbes MK, Tackett JL, Markon KE, Krueger RF. Beyond comorbidity: toward a dimensional and hierarchical approach to understanding psychopathology across the life span. Dev Psychopathol. 2016 Nov;28(4pt1):971-86.

10 Tackett J, Herzhoff K, Balsis S, Cooper L. Toward a unifying perspective on personality pathology across the lifespan. In: Cichetti DC, editor. Developmental psychopathology. New York: Wiley; 2016. p. 1039-78.

11 Tackett JL, Herzhoff K, Reardon KW, De Clercq B, Sharp C. The externalizing spectrum in youth: incorporating personality pathology. J Adolesc. 2014 Jul;37(5):659-68.

12 Shiner RL. A developmental perspective on personality disorders: lessons from research on normal personality development in childhood and adolescence. J Pers Disord. 2005 Apr;19(2):202-10.

13 Shiner R, Caspi A. Personality differences in childhood and adolescence: measurement, development, and consequences. J Child Psychol Psychiatry. 2003 Jan;44(1):2-32.

14 Rothbart MK, Derryberry D. Development of individual differences in temperament [1981]. Adv Dev Psychol. 2013;1:37-86.

15 Thomas A, Chess S. Temperament and development. New York: Bruner/Mazel; 1977.

16 Ahadi SA, Rothbart MK, Ye RM. Children's temperament in the US and China: similarities and differences. Eur J Pers. 1993;7(5): 359-78.
17 Rothbart MK. Temperament, development, and personality. Curr Dir Psychol Sci. 2007; 16(4):207-12.

18 Ormel J, Oldehinkel AJ, Ferdinand RF, Hartman CA, De Winter AF, Veenstra R, et al. Internalizing and externalizing problems in adolescence: general and dimension-specific effects of familial loadings and preadolescent temperament traits. Psychol Med. 2005 Dec; 35(12):1825-35.

19 Goldberg LR. Analyses of Digman's childpersonality data: derivation of Big-Five factor scores from each of six samples. J Pers. 2001 Oct;69(5):709-43.

20 Caspi A, Roberts BW, Shiner RL. Personality development: stability and change. Annu Rev Psychol. 2005;56(1):453-84.

21 Verbeke L, De Caluwé E, De Clercq B. A fivefactor model of developmental personality pathology precursors. Pers Disord. 2017 Apr; 8(2):130-9.

22 De Clercq B, Decuyper M, De Caluwé E. Developmental manifestations of borderline personality pathology from and age-specific dimensional personality disorder trait framework. In: Sharp C, Tackett JL, editors. Handbook of borderline personality disorder in children and adolescents. New York: Springer; 2014. p. 81-94.

23 Sharp C, Kerr S, Chanen A. Prevention and early identification and prevention of personality pathology: an AMPD informed model of clinical staging. In: Oldham J, Skodol A, editors. The American Psychiatric Publishing Textbook of Personality Disorders. Washington: American Psychiatric Association [under review].

24 Sharp C. Current trends in BPD research as indicative of a broader sea-change in psychiatric nosology. Pers Disord. 2016 Oct;7(4): 334-43.

25 Chanen A, Sharp C, Hoffman P; Global Alliance for Prevention and Early Intervention for Borderline Personality Disorder. Prevention and early intervention for borderline personality disorder: a novel public health priority. World Psychiatry. 2017 Jun;16(2):215-6.

26 Sharp C. Bridging the gap: the assessment and treatment of adolescent personality disorder in routine clinical care. Arch Dis Child. 2017 Jan;102(1):103-8.

27 Sharp C, Kalpakci A. If it looks like a duck and quacks like a duck: evaluating the validity of borderline personality disorder in adolescents. Scand J Child Adolesc Psychol Psychiatry. 2015;3(1):49-62.

28 Sharp C, Kim S. Recent advances in the developmental aspects of borderline personality disorder. Curr Psychiatry Rep. 2015 Apr; 17(4):556

29 Zanarini MC, Horwood J, Wolke D, Waylen A, Fitzmaurice G, Grant BF. Prevalence of DSM-IV borderline personality disorder in two community samples: 6,330 English 11-year-olds and 34,653 American adults. J Pers Disord. 2011 Oct;25(5):607-19.
30 Johnson JG, Cohen P, Kasen S, Skodol AE, Oldham JM. Cumulative prevalence of personality disorders between adolescence and adulthood. Acta Psychiatr Scand. 2008 Nov; 118(5):410-3.

31 Leung SW, Leung F. Construct validity and prevalence rate of borderline personality disorder among Chinese adolescents. J Pers Disord. 2009 Oct;23(5):494-513.

32 Cohen P, Crawford TN, Johnson JG, Kasen S. The children in the community study of developmental course of personality disorder. J Pers Disord. 2005 Oct;19(5):466-86.

33 Stepp SD, Lazarus SA, Byrd AL. A systematic review of risk factors prospectively associated with borderline personality disorder: taking stock and moving forward. Pers Disord. 2016 Oct;7(4):316-23.

34 Bornovalova MA, Hicks BM, Iacono WG, McGue M. Longitudinal twin study of borderline personality disorder traits and substance use in adolescence: developmental change, reciprocal effects, and genetic and environmental influences. Pers Disord. 2013 Jan;4(1):23-32.

35 Penner F, McLaren V, Leavitt J, Akca OF, Sharp C. Implicit and explicit mentalizing deficits in adolescent inpatients: specificity and incremental value of borderline pathology. J Pers Disord. doi: 10.1521/pedi_ 2019_33_463 [Epub ahead of print].

36 Sharp C, Green KL, Yaroslavsky I, Venta A, Zanarini MC, Pettit J. The incremental validity of borderline personality disorder relative to major depressive disorder for suicidal ideation and deliberate self-harm in adolescents. J Pers Disord. 2012 Dec;26(6):927-38.

37 Chanen A, Jackson H, McCutcheon L, Germano D, Nistico H, Dudgeon P, et al. 02-08 A randomized controlled trial of psychotherapeutic early intervention for borderline personality disorder. Acta Neuropsychiatr. 2006 Dec;18(6):319.

38 Ibraheim M, Kalpakci A, Sharp C. The specificity of emotion dysregulation in adolescents with borderline personality disorder: comparison with psychiatric and healthy controls. Borderline Personal Disord Emot Dysregul. 2017 Jan;4(1): 1.

39 Sharp C, Pane H, Ha C, Venta A, Patel AB, Sturek J, et al. Theory of mind and emotion regulation difficulties in adolescents with borderline traits. J Am Acad Child Adolesc Psychiatry. 2011 Jun;50(6):563-73.e1.

40 Jones J, Penner F, Schramm AT, Sharp C. Experiential avoidance in adolescents with borderline personality disorder: comparison with a non-BPD psychiatric group and healthy controls. Cogn Behav Ther. 2020 May;49(3):197-209.

41 Cristea IA, Gentili C, Cotet CD, Palomba D, Barbui C, Cuijpers P. Efficacy of Psychotherapies for Borderline Personality Disorder: A Systematic Review and Meta-analysis. JAMA Psychiatry. 2017 Apr;74(4):319-28.
The Alternative Model for Personality Disorders
Psychopathology 2020;53:198-204 DOI: $10.1159 / 000507588$ 
42 Robins E, Guze SB. Establishment of diagnostic validity in psychiatric illness: its application to schizophrenia. Am J Psychiatry. 1970 Jan;126(7):983-7.

43 Widiger TA, Trull TJ. Plate tectonics in the classification of personality disorder: shifting to a dimensional model. Am Psychol. 2007 Feb-Mar;62(2):71-83.

44 Krueger RF, Eaton NR, Clark LA, Watson D, Markon KE, Derringer J, et al. Deriving an empirical structure of personality pathology for DSM-5. J Pers Disord. 2011 Apr;25(2): 170-91.

45 Clark LA. Assessment and diagnosis of personality disorder: perennial issues and an emerging reconceptualization. Annu Rev Psychol. 2007;58(1):227-57.

46 Sharp C. Editorial: What's in a name? The importance of adolescent personality pathology for adaptive psychosocial function. J Am Acad Child Adolesc Psychiatry. doi: 10.1016/ j.jaac.2019.10.007 [Epub ahead of print].

47 Sharp C. Calling for a Unified Redefinition of "Borderlineness": commentary on Gunderson et al. J Pers Disord. 2018 Apr;32(2):16874.

48 Sharp C, Vanwoerden S, Wall K. Adolescence as a sensitive period for the development of personality disorder. Psychiatr Clin North Am. 2018 Dec;41(4):669-83.

49 Sharp C, Wall K. Personality pathology grows up: adolescence as a sensitive period. Curr Opin Psychol. 2018 Jun;21:111-6.

50 Sharp C, Wright AG, Fowler JC, Frueh BC, Allen JG, Oldham J, et al. The structure of personality pathology: both general ("g") and specific ("s") factors? J Abnorm Psychol. 2015 May;124(2):387-98.
51 Wright AG, Hopwood CJ, Skodol AE, Morey LC. Longitudinal validation of general and specific structural features of personality pathology. J Abnorm Psychol. 2016 Nov;125(8): 1120-34.

52 Wright AG, Simms LJ. A metastructural model of mental disorders and pathological personality traits. Psychol Med. 2015 Aug; 45(11):2309-19.

53 Clark LA, Ro E. Three-pronged assessment and diagnosis of personality disorder and its consequences: personality functioning, pathological traits, and psychosocial disability. Pers Disord. 2014 Jan;5(1):55-69.

54 Sharp C, Criterion A. Putting the person back into person(ality) disorder. In: Widiger T, editor. Oxford Handbook of Personality Disorders. Oxford: Oxford University Press [under review].

55 Kernberg O. Borderline personality organization. J Am Psychoanal Assoc. 1967 Jul;15(3): 641-85.

56 Caspi A, Houts RM, Belsky DW, GoldmanMellor SJ, Harrington H, Israel S, et al. The $\mathrm{p}$ factor: one general psychopathology factor in the structure of psychiatric disorders? Clin Psychol Sci. 2014 Mar;2(2):119-37.

57 Morey LC. Development and initial evaluation of a self-report form of the DSM-5 Level of Personality Functioning Scale. Psychol Assess. 2017 Oct;29(10):1302-8.

58 Rosen K. Social and emotional development: attachment relationships and the emerging self. London, UK: Macmillan Education; 2016.

59 Erikson E. Childhood in society. New York: Norton; 1950.
60 Steinberg L, Dahl R, Keating D, Kupfer DJ, Masten AS, Pine DS. The study of developmental psychopathology in adolescence: integrating affective neuroscience with the study of context. In: Cicchetti D, Cohen D, editors. Developmental psychopathology. New York: Wiley; 2006. p. 710-41.

61 Harter S. Emerging self-processes during childhood and adolescence. In: Leary MR, Tangney P, editors. Handbook of self and identity. New York: Guilford Press; 2012. p. 680-715.

62 McAdams DP, Olson BD. Personality development: continuity and change over the life course. Annu Rev Psychol. 2010;61(1):51742.

63 Allen JP, Loeb EL. The Autonomy-Connection Challenge in Adolescent Peer Relationships. Child Dev Perspect. 2015 Jun;9(2):1015.

64 Allen JP, Chango J, Szwedo D, Schad M, Marston E. Predictors of susceptibility to peer influence regarding substance use in adolescence. Child Dev. 2012 Jan-Feb;83(1):33750.

65 Pfeifer JH, Blakemore SJ. Adolescent social cognitive and affective neuroscience: past, present, and future. Soc Cogn Affect Neurosci. 2012 Jan;7(1):1-10.

66 Montgomery MJ. Psychosocial intimacy and identity: from early adolescence to emerging adulthood. J Adolesc Res. 2005;20(3):346-74.

67 Rutter M, Rutter M. Developing minds: Challenge and continuity across the lifespan. London: Basic Books; 1993.

68 Sharp C, Rossouw T. Working with borderline teens. In: Bateman A, Fonagy P, editors. Handbook of mentalizing in mental health practice. 3rd ed. New York: Wiley; 2019. p. $281-300$ 